\title{
Organización y liderazgo de migrantes indígenas en México y Estados Unidos. El caso del FIOB
}

\author{
LAURA VELASCO ORTIZ*
}

RESUMEN: Este artículo presenta una reflexión sobre los posibles cambios en los liderazgos indígenas surgidos en diferentes contextos locales donde el Frente Indígena de Organizaciones Binacionales está activo en ambos lados de la frontera México-Estados Unidos. El objetivo es cuestionar las visiones duales de estos liderazgos, recuperando la visión emic de los activistas y las propias prácticas de los liderazgos en la organización, así como hacer un acercamiento al tema del reemplazo generacional en un contexto donde parece clara la existencia de un proyecto político transnacional, pero con fuertes tensiones con la política étnica local de cada país.

PALABRAS CLAVE: liderazgos indígenas transnacionales, transnacionalismo étnico, organizaciones transnacionales, FIOB, migración indígena México-Estados Unidos.

\footnotetext{
* Investigadora del Departamento de Estudios Culturales de El Colegio de la Frontera Norte, México.
} 
ABSTRACT: This article presents a reflection on possible changes in indigenous leaderships in different local contexts where the Indigenous Front of Binational Organizations is active on both sides of the US-Mexico border. The aim is to question the dual visions of these leaderships, recovering the emic view of activists and practices of leaders within the organization, and to make an approach to the generational replacement issue in what appears to be a clear transnational political project, but with tensions with the local ethnic politics of each country.

KEYWORDS: indigenous transnational leaderships, ethnic transnationalism, transnational organizations, $\mathrm{FIOB}$, indigenous migration from Mexico to the United States. 


\section{INTRODUCCIÓN}

ombrar «mexicanos» a todos los inmigrantes que proceden de
las distintas regiones de México encubre la gran diversidad
de orígenes regionales, locales y étnicos existente en el país.
Oaxaca es uno de los estados que puede ejemplificar claramente una migración internacional diferenciada en términos étnicos, respecto de otros estados ya sean tradicionales o emergentes. La amplia bibliografía sobre la migración mixteca y zapoteca muestra que la adscripción étnica y local posee una fuerte vitalidad entre los inmigrantes oaxaqueños establecidos en distintos lugares de México y de Estados Unidos. Existe una energía comunitaria intensa en los núcleos de inmigrantes en distintos lugares de Estados Unidos, las formas organizativas de orden local, las asociaciones propueblos y las organizaciones étnicas y panétnicas.

Como Bonfil (1995: 122-124) lo señaló hace más de dos décadas al observar la migración interna de indígenas a las urbes, la formación de organizaciones en los nuevos lugares de asentamiento se acompañó de nuevas formas de liderazgos que acumulaban la experiencia milenaria de las comunidades indígenas rurales con las experiencias populares de los inmigrantes en los nuevos barrios urbanos de las grandes ciudades mexicanas. Después de casi medio siglo de un flujo constante y creciente de migrantes oaxaqueños, las observaciones de Bonfil parecen tener vigencia al tratar de comprender el cambio de las formas organizativas de los inmigrantes y los liderazgos de origen mixteco y zapoteco en California y la frontera norte de México.

Este artículo presenta una reflexión sobre la tensión producida entre lo local y lo transnacional para la constitución de los liderazgos, así como sobre el reto del cambio generacional para las organizaciones autonombradas indígenas, las cuales se han formado en la experiencia de la migración a la frontera y a Estados Unidos, desde los años ochenta del siglo xx. La base empírica de esta reflexión se nutre de distintos momentos de investigación sobre el Frente Indígena de Organizaciones Binacionales (FIOB). Entre 1994 y 2000 fue reconstruido el campo de las organizaciones indígenas migrantes oaxaqueñas en la frontera de Baja California y California y su conexión con los pueblos 
de origen, teniendo como foco de estudio al Frente Indígena Oaxaqueño Binacional (Velasco, 2005). Después, de 2001 a 2004 fue sistematizada la evolución de esta organización con distintas formas organizativas surgidas en los distintos lugares del corredor agrícola del noroeste y de ciudades como el Distrito Federal y Oaxaca, es decir, con la migración indígena interna (Velasco, 2005). De 2005 a 2008 se desarrolló un proyecto de colaboración a invitación del FIOB, para realizar un taller en cada una de sus sedes estatales: Oaxaca, Baja California y California, con la finalidad de investigar cómo llevar a cabo la renovación de liderazgos dada la condición de dispersión de los miembros de la organización producto de la migración internacional (Romero-Hernández et al., 2013). Y finalmente, entre 2011 y 2013 se dio seguimiento a la investigación con jóvenes indígenas de segunda generación con la finalidad de indagar sobre la relación con el origen étnico y su peso en la formación como activistas ligados al FIOB o independientes (Hernández, 2012).Con base en este conjunto de investigaciones es viable la hipótesis de la transformación de los liderazgos a partir de la constitución de organizaciones que responden a distintos contextos locales pero en un horizonte político transnacional. Hay una acumulación de experiencias políticas de los distintos lugares de la migración que condensan lo urbano-popular, con los movimientos agrícolas del norte y con las luchas migrantes en Estados Unidos. La condición de dispersión geográfica dificulta generar una acción colectiva estratégica pero a la vez ha traído nuevas experiencias sociales y políticas ampliando el universo de intereses y recursos de la organización, así como de sus alianzas políticas. La riqueza de experiencias se expresa en una multiplicidad de liderazgos que promueven una diversidad de proyectos colectivos al interior del campo organizativo fragmentado por la fuerza de lo local pero a la vez transnacional. Esta complejidad no parece desdibujar el discurso étnico, pero sí su contenido. Dada la complejidad de la tarea, en este artículo sólo se intenta analizar cómo los diferentes contextos locales de producción de liderazgos de primera y segunda generación se articulan en un proyecto transnacional y hacer un acercamiento al reemplazo generacional. El cuerpo del texto está organizado con base en los resultados de los tres talleres realizados entre 2005 y 2006 con miembros del fioB en Oaxaca, Baja California y California; en con-

$100 \frac{\text { SEGUNDO SEMESTRE } 2014}{\text { MIGRACIÓN Y DESARROLLO NÚM. } 23}$ 
junto, los talleres permiten un acercamiento simultáneo de las fuerzas locales en el horizonte común que les otorga la migración internacional.

\section{UN ACERCAMIENTO CONCEPTUAL A LOS LIDERAZGOS DE MIGRANTES INDÍGENAS EN UN CAMPO TRANSNACIONAL}

¿Cómo conceptuar los liderazgos indígenas de una organización como la que nos ocupa, tratando de recuperar las diversas fuentes históricas que los nutre y los diferentes contextos locales? A principios de los años noventa, Bonfil (1995) nos alertaba de las novedades que había traído la migración en la definición de los liderazgos indígenas, más allá de la idea de autoridad tradicional indígena. En tanto que Bartolomé (1997: 170) señala la confusión entre autoridades tradicionales y líderes comunitarios. Para este autor, la autoridad tradicional no implica ningún tipo de «representación", sino sólo el papel de «orador que guía» en el sentido ético. Estos señalamientos surgen a raíz precisamente del surgimiento de un gran número de liderazgos comunitarios en los lugares de migración indígena como parte del proceso de urbanización en las ciudades o bien de los asentamientos en Estados Unidos y su importante papel en la integración e intermediación de las comunidades migrantes.

En esta investigación también se distingue la autoridad tradicional indígena y los liderazgos indígenas. Se entiende por liderazgo el proceso a través del cual una persona o varias (ya sea por sus atributos reales o atribuidos) tienen seguidores. De esta forma, el liderazgo no existe sin el reconocimiento de los seguidores. Esta relación entre el que dirige y el dirigido, es lo que lleva a Bourdieu (1982) a decir que el dirigente existe gracias al grupo que lo hace dirigente a la vez. Mientras la tarea organizativa es interna, la tarea de dirigir es externa y exige el papel de mediación y representación entre el nosotros y los «otros», sean aliados o adversarios. De acuerdo con Bartolomé (1997: 170), la autoridad indígena siempre implica una posición formal dentro de un sistema institucional y normativo, donde existen jerarquías y funcio- 
nes definidas por la costumbre o la ley, lo que Hernández y Selee (2013) llaman gobierno local indígena. De esta forma, la base de la legitimidad de la autoridad indígena emana de la tradición y el gobierno comunitario, en tanto que la del liderazgo indígena emana de su capacidad organizativa y de intermediación en un sistema político externo. Para analizar los liderazgos producto de las relaciones interétnicas que produce la migración internacional es necesario introducir a los agentes del Estado-nación. Tanto la producción de una política étnica como de extranjería son áreas de gran actividad e interés para los Estados nacionales contemporáneos.

Con este razonamiento, se plantea la posibilidad de considerar a estos líderes indígenas como agentes étnicos (Velasco, 2005: 128-129) antes que «intelectuales orgánicos» (Gramsci, 1998), asumiendo que no existe una relación orgánica única entre dirigentes y dirigidos, o líderes y bases, sino que los vínculos pueden ser de clase, locales, étnicos, de ciudanía, género y generación; y a la vez que hay un cambio de la relación orgánica con la comunidad territorial y que muy frecuentemente los líderes juegan el papel de intermediarios y a la par voceros o representantes de los núcleos o comunidades a las que se adscriben.

La tarea es rastrear la imbricación del contexto local de organización y de producción de liderazgos en un campo organizativo transnacional (FIOB), al mismo tiempo que describir el cambio generacional avizorado por las propias organizaciones y que en estos momentos parece más evidente sobre todo en Estados Unidos con el movimiento de los Dreamers. ${ }^{1}$ El cambio generacional puede observarse también como un resultado del proceso de asentamiento de los inmigrantes indígenas en Estados Unidos. El horizonte cultural de la agencia individual de estos protagonistas es un tema de interés

${ }^{1}$ Los dreamers son jóvenes que llegaron a Estados Unidos siendo niños y no cuentan con documentos que les permitan tener una estancia legal. Una parte espera regularizar su situación migratoria con la Reforma "DreamAct» (DreamAct, 2001). Otros han sido beneficiados con la Acción Diferida (Deferred Action for Childhood Arrivals —DACA—, 2012), la cual establece que durante un periodo de dos años y sujeto a renovación, los jóvenes pueden acceder a un empleo e incluso tener una licencia de conducir, lo cual no implica un estatus legal. Esto cambiará con la Acción Ejecutiva anunciada por el presidente Barack Obama el 20 de noviembre de 2014.

$102 \frac{\text { SEGUNDO SEMESTRE } 2014}{\text { MIGRACIÓN Y DESARROLLO NÚM. } 23}$ 
en este artículo, en la medida en que se considera que la reafirmación identitaria es un medio en la lucha contra la exclusión y discriminación.

El estudio de los líderes y activistas de estas organizaciones ha recibido escasa atención en la literatura dedicada a las organizaciones de migrantes. ${ }^{2}$ La importancia de los liderazgos va más allá del estudio de las organizaciones porque, como lo señala Edelman (2003: 4), aun cuando las organizaciones puedan desaparecer, los activistas permanecen, acumulando experiencias y transfiriéndolas a otras luchas. El seguimiento de las biografías de los líderes mixtecos (Velasco, 2005) ha permitido conectar movimientos sociales aparentemente desconectados, como son el movimiento indígena de los años setenta, con el movimiento popular y obrero, y a la vez con los movimientos de jornaleros agrícolas de los años ochenta en México y con la lucha de principios del siglo XXI de los inmigrantes y las recientes luchas de los jóvenes soñadores (Dreamers) en Estados Unidos. Melucci (1999: 38) señala que en innumerables ocasiones lo único observable de los movimientos sociales son los liderazgos.

El estudio de las organizaciones y liderazgos permite un acercamiento a los obstáculos de la integración local y las fuerzas transnacionales que definen ese proceso, así como los cambios generacionales que están sucediendo. ¿H Hasta qué punto estos liderazgos están reflejando los cambios generacionales y de género que están viviendo estas comunidades de migrantes? En la medida en que existe una diferenciación social interna en las comunidades (de origen, destino y tránsito), las organizaciones también se transforman no sólo en su demografía y prácticas, sino en el tipo de liderazgos.

\section{Contextos locales y pRoyectos políticos tRansNacionales}

El Frente Indígena de Organizaciones Binacionales tiene su antecedente más remoto en el Frente Indígena Mixteco-Zapoteco Binacional, fundado en

${ }^{2}$ Aun cuando existe una literatura suficiente sobre las organizaciones de migrantes, la atención en los liderazgos ha sido muy escasa (véase Rivera-Salgado y Escala, 2005). 
1991 en la ciudad de Los Ángeles, California. Desde entonces ha habido una recomposición de su membrecía y liderazgos que en cierta forma refleja el desenvolvimiento de la migración internacional y los retos de la acción colectiva en lugares urbanos y rurales, a la vez que en México y Estados Unidos. Tal recomposición y la tensión entre lo local y lo transnacional puede observarse en cuatro momentos distintos:

a. En 1994 con la Asamblea Binacional realizada en la ciudad de Tijuana, donde asistieron activistas y migrantes de origen mixteco, zapoteco, triqui y mixe, y donde la organización tomó el nombre de Frente Indígena Oaxaqueño Binacional. En esta asamblea los participantes expresaron su adhesión al movimiento zapatista originado en el estado de Chiapas.

b. En 2004 con la Asamblea Binacional realizada en la ciudad de Oaxaca. En este momento se habían integrado activistas y organizaciones purépechas de Michoacán. Para dar cabida a tal diversidad étnica la organización cambió de nombre al actual Frente Indígena de Organizaciones Binacionales, quedando registrado finalmente en marzo de 2005.

c. En 2011, festejando sus 20 años, la organización convoca a la Asamblea General Binacional en la ciudad de Oaxaca con el nombre de Frente Indígena de Organizaciones Binacionales, donde aparecen en la agenda dos mesas de trabajo: «Migración y Desarrollo y el Derecho a No Migrar» y «La Política Migratoria Binacional». ${ }^{3}$

d. Finalmente la última asamblea realizada el mes de octubre de 2014 en la misma ciudad de Oaxaca a la que asistieron cerca de 250 delegados de Oaxaca, Baja California y California, e incluyeron en su agenda el tema "Crisis de las Políticas Migratorias Binacionales», y en el transcurso de la asamblea se agregaron las mesas de "Género» y "Jóvenes», con el tema del relevo generacional de los liderazgos.

Esta trayectoria define en la actualidad al ғіов соmo un agente político que actúa localmente con un proyecto transnacional. Es decir, lo que en

${ }_{3}^{3}$ Véase la convocatoria a la Asamblea General Binacional, en: http://fiob.org/2011/07/listoel-fiob-para-su-asamblea-general-binacional/(consultado el 10 de octubre de 2014).

$104 \frac{\text { SEGUNDO SEMESTRE } 2014}{\text { MIGRACIÓN Y DESARROLLO NÚM. } 23}$ 
términos empíricos se observa es un conjunto de activistas organizados bajo un sistema de normas y reglas, con una cierta división del trabajo y que actúa en forma local en un campo político transnacional, aun cuando los comités regionales desarrollen intereses locales. ${ }^{4}$

El FIOB, como otras organizaciones de migrantes, guarda una estructura multilocal para dar cuenta de la multiplicidad residencial de los activistas y de los que pretenden representar. Estos diferentes contextos sociales y políticos constituyen una línea de diferenciación espacial de la organización que se encuentra con otras líneas de diferenciación como las generacionales y las de género. Como lo advierte Smelser (2003), uno de los retos más urgentes cuando se observa un fenómeno que sucede en contextos distintos es la sistematización de tales contextos, con la finalidad de tener algún grado de certeza de que estamos ante un mismo fenómeno. Cada contexto local produce condiciones distintas de la acción colectiva, que a su vez afecta la propia constitución del agente. Esta idea podrá comprenderse mejor si pensamos en las diferencias entre las organizaciones de migrantes que proceden de la misma región de origen, que tienen formas tan distintas en Baja California y California.

\section{Migrantes e indigenas:}

el contexto de los liderazgos locales y transnacionales

La coyuntura de 2005, con el cambio hacia una organización panétnica más allá de lo oaxaqueño, define un horizonte binacional novedoso. ${ }^{5}$ En el año de 2006 hubo dos grandes focos de movilización que concentraron la energía de la organización: los movimientos pro-migrantes en California desarrollados

${ }^{4}$ Para Touraine (1981) un movimiento social se define, entre otros elementos, por la lucha del control social de la historicidad.

${ }^{5}$ Como ya se mencionó en el texto, en 2005 la Asamblea General Binacional decidió cambiar el nombre de Frente Indígena Oaxaqueño Binacional por el de Frente Indígena de Organizaciones Binacionales para dar cabida a grupos u organizaciones indígenas que no están en el estado de Oaxaca. 
a partir de la oposición a la iniciativa Sensenbrenner ${ }^{6}$ en el Senado de Estados Unidos y el movimiento de la Asamblea Popular de los Pueblos de Oaxaca (APPO), surgida a raíz del movimiento magisterial y difundida a las organizaciones populares que, entre muchas demandas, exigían la renuncia del entonces gobernador de Oaxaca, Ulises Ruiz Ortiz. ${ }^{7}$ Estos dos movimientos, de alguna forma ejemplifican las fuerzas políticas que anidan en el seno de la organización durante el primer quinquenio del siglo XXI.

En relación con el movimiento indígena, hay un amplio reconocimiento de que el FIOB es parte de ese movimiento en México y en América Latina y de que sus demandas están en el marco de los derechos de los pueblos indígenas como se manifestó en la asamblea de 1994. Sin embargo, en cada región se expresa una interpretación y posicionamiento distinto en torno a la urgencia de ese tema. Por ejemplo, en los últimos cinco años se han realizado casi 4.6 millones de deportaciones, con un porcentaje de alrededor de 6.5 por ciento de hablantes de lengua (Velasco y Coubès, 2013). En California existe una gran urgencia por posicionarse como organización frente a este tema, antes que a la discriminación indígena.

\section{Los Ángeles, California: inmigrantes e indígenas}

Si bien los activistas de las diferentes regiones se reconocen vinculados de una u otra forma al movimiento por los derechos de los migrantes, la urgencia proviene de los comités de California. En 2006, el FIOB en California se encontraba integrado en una coalición para la defensa de los derechos de inmigrantes. Junto con otras organizaciones pro-migrantes, el FIOB logró movilizar entre 13,000 y 20,000 personas en el valle agrícola de San Joaquín, California, un número nunca antes visto en el valle; de la misma forma, logró

${ }^{6}$ En 2005, el presidente del Comité de Asuntos Judiciales de la Cámara Baja, F. James Sensenbrenner, republicano de Wisconsin, propuso un proyecto migratorio con énfasis en la seguridad fronteriza y mayores controles en los centros de trabajo (Ley de 2005 para la Protección Fronteriza, Antiterrorismo y Control de la Inmigración Indocumentada).

7 La participación de las mujeres oaxaqueñas en este movimiento popular es documentada por Stephen (2007).

$106 \frac{\text { SEGUNDO SEMESTRE } 2014}{\text { MIGRACIÓN Y DESARROLLO NÚM. } 23}$ 
un contingente en la marcha multitudinaria del 25 de marzo del 2006 en Los Ángeles, en protesta a la Ley Sensenbrenner. Los activistas hacen un recuento de cómo la participación en las movilizaciones pro-derechos de los inmigrantes fue un momento crítico para la organización. En Los Ángeles los miembros de la comunidad oaxaqueña participaban principalmente en fiestas o eventos culturales, y como lo reseñaron varios activistas, no había una práctica de ir a la calle a protestar. La presencia de los inmigrantes oaxaqueños en el espacio público se ha ligado a la reproducción festiva o culinaria, o al vínculo con su localidad de origen, antes que a la protesta por su condición de inmigrantes.

Las discusiones en las reuniones, asambleas y talleres de 2005-2006 expresan una conciencia clara de su especificidad como movimiento inmigrante e indígena en California. Su evaluación es que al interior del movimiento migrante son los únicos con una composición y proyecto indígena, lo cual constituye una oportunidad y un reto al mismo tiempo, porque frecuentemente su identidad y demandas indígenas son borradas por el movimiento más amplio de inmigrantes y en otras ocasiones el FIOB es reconocido como una de las pocas organizaciones que trabajan con los pueblos indígenas migrantes de México.

Por otro lado, el FIOB en Los Ángeles incrementó su número de miembros con las movilizaciones en solidaridad con Oaxaca (su estado de origen). Durante 2006, se formó un comité de apoyo a la Asamblea Popular de los Pueblos de Oaxaca (APPO) en Los Ángeles, el cual recaudó fondos entre la comunidad oaxaqueña para ser enviados a Oaxaca con la finalidad de subsanar distintos gastos de las movilizaciones populares. Fueron famosas las «AProposadas», que conjuntaban una tradición católica mexicana con una acción de solidaridad política con su lugar de origen desde la distancia geográfica. La naturaleza de estas prácticas no es distinta de las que realizan otros grupos migrantes actualmente o han realizado en el pasado. Su especificidad se encuentra en su actividad de oposición al gobierno local, lo que los distancia de otras organizaciones o asociaciones de migrantes que mantienen relaciones de colaboración estrecha con los gobiernos estatales originarios. Sin embargo, en la última década esto ha cambiado notoriamente. 
Un miembro fundador del ғіов fue incorporado al gabinete del gobernador de Oaxaca en el área de atención a los migrantes. También, el movimiento magisterial de Oaxaca ha tenido un fuerte impacto en el FIOB, a tal grado que en la asamblea recién realizada en 2014 fue electo Ezequiel Rosales, exdirigente de la Sección 22 del Sindicato Nacional de Trabajadores de la Educación (SNTE) $)^{8}$ como coordinador estatal en Oaxaca.

En relación con el movimiento indígena, en California se reconoce al FIOB como parte del movimiento de los derechos indígenas, aun cuando existe una falta de familiaridad con las organizaciones de indios nativos o nativos estadounidenses. Hay antecedentes de encuentros entre pueblos indígenas migrantes y nativos estadounidenses y hay indicios suficientes acerca de que se reconocen mutuamente como contrapartes. Sin embargo, como lo señala Jesús Estrada Velasco, coordinador estatal del fioв en California, existe tensión entre nativos y migrantes en torno al territorio. Jesús fue invitado por un activista local chumash ${ }^{9}$ para asistir a la radio American Indian Airwaves, y tratar el tema de la migración indígena: «[...] Las naciones indígenas en Estados Unidos están siendo afectadas negativamente por la migración y no han recibido información que contrarreste la difundida por los medios masivos, la cual culpabiliza a los inmigrantes latinos». ${ }^{10}$ Aquí lo transnacional, como naciones indígenas, muestra su debilidad por la condición inmigrante.

El encuentro con otros movimientos sociales parece indicar la existencia de temporalidades distintas en cada lucha. En tanto la lucha de los indios americanos fue más visible en los años setenta con organizaciones como Movimiento de Indios Americanos (AIM); el movimiento indígena en México inició en los años ochenta y logró un momento cúspide en los noventa con el movimiento zapatista y la efervescencia actual en torno a la defensa de los territorios y sus recursos naturales, como la de los yaquis en Sonora. Esto hace que exista una especie de desalineación de ambos movimientos en

${ }^{8}$ Sección 22 del Sindicato Nacional de Trabajadores de la Educación (SNTE), adherente a la Coordinadora Nacional de Trabajadores de la Educación (CNTE).

9 Pueblo nativo estadounidense localizado en California.

${ }^{10}$ Entrevistas realizadas por Laura Velasco en la ciudad de Los Ángeles el 21 de enero de 2007.

$108 \frac{\text { SEGUNDO SEMESTRE } 2014}{\text { MIGRACIÓN Y DESARROLLO NÚM. } 23}$ 
términos temporales, ya que las organizaciones de los indios estadounidenses están mucho más institucionalizadas, con un papel claro en la construcción de la nación estadounidense, en tanto que las organizaciones indígenas migrantes están menos institucionalizadas y se encuentran entre configuraciones étnicas de dos Estados nacionales. El censo de 2000 registró 407,073 indios hispanoamericanos y en 2010 un incremento casi de 50 por ciento con 685,150 , con 40 por ciento en California. Estos indios latinoamericanos son indígenas migrantes de origen mexicano y de los países de América Central.

Tijuana, Baja California: migrantes vs. residentes

Al sur de California (véase mapa 1), en el seno del fiob-Baja California, persiste una polémica que afloró en los talleres de 2005-2006, sobre la existencia y las características de un movimiento migrante. Entre los líderes y activistas de Baja California hay un cuestionamiento al concepto de inmigrante, aludiendo a que el uso de este concepto los excluye de los derechos que como ciudadanos tienen en este estado. Frente al concepto de inmigrante se antepone el de residente, con la connotación de una persona que está ya residiendo en forma permanente en la región (Romero-Hernández et al., 2013). Por lo que a las demandas relacionadas con los derechos humanos y laborales, también se agregan las que corresponden a su estatus como residentes y ciudadanos de Baja California.

[...] no me gusta que me llamen migrante. ¿̇Quién me puso así? Porque el mismo diputado o gobierno me llama migrante para que no tenga derechos. Estoy convenciendo a los hermanos indígenas nativos de Baja California ${ }^{11}$ para tener un acuerdo como indígenas para hablar de indígenas residentes de Baja California y llevarlo a la cámara de diputados (Julio Sandoval). ${ }^{12}$

Aquí de nuevo, como en Estados Unidos, surge la relación con los indígenas nativos. Demográficamente diezmados, los indígenas nativos cucapás,

${ }^{11}$ En Baja California, 98 por ciento de la población indígena hablan una lengua de origen inmigrante, en su mayoría procedente de Oaxaca (INEGI, 2000).

${ }^{12}$ Dirigente del Movimiento Indígena por la Unificación y Lucha Independiente (MIULI), Taller FIOB, 26 de noviembre de 2006, Tijuana, B.C. 


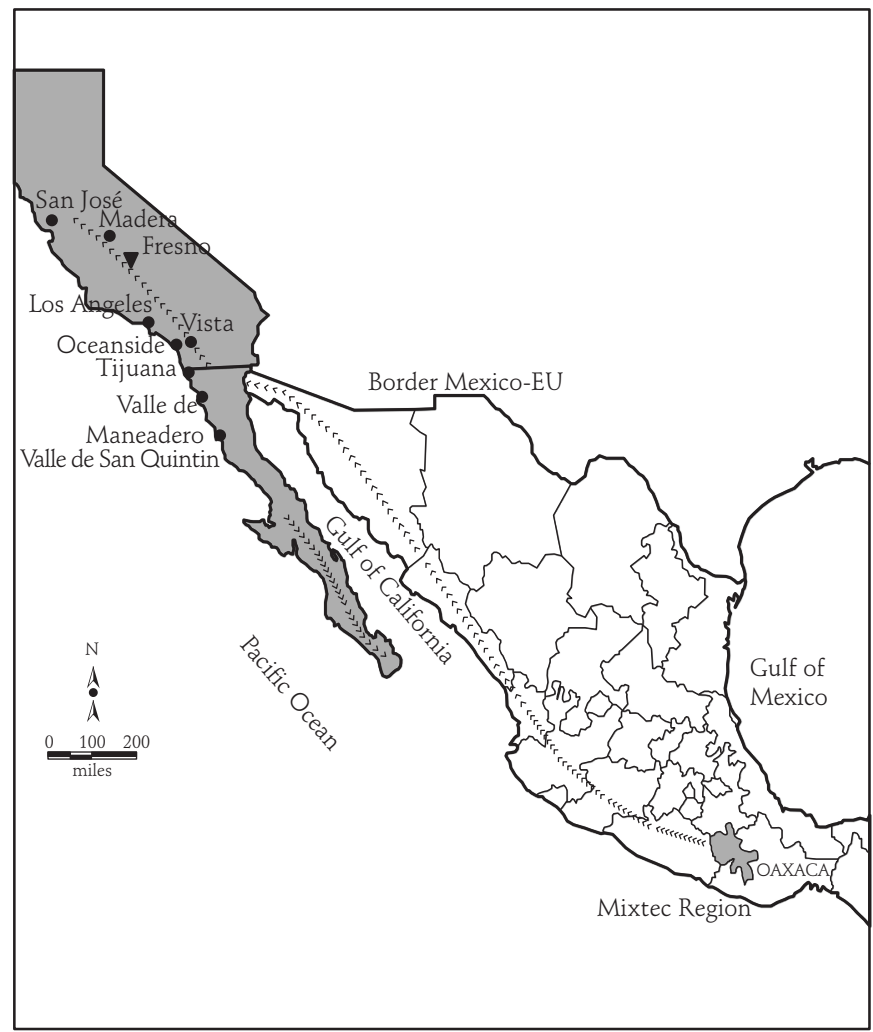

Fuente: Elaborado por el Sistema de Información Geográfica y Estadística Fronteriza (SIGEF) de El Colegio de la Frontera Norte.

kumiai, kiliwas y paipai viven en competencia por los recursos del Estado con los indígenas inmigrantes; con especial efervescencia en el terreno de la educación bilingüe e intercultural de las escuelas primarias (véase Velasco, 2005), ya que la población escolar de origen inmigrante es más numerosa que la nativa. Sin embargo, esta relación de competencia produce un estado de avivamiento y visibilidad de lo étnico en Baja California.

Este desalineamiento espacial se debe a que los procesos de arraigo en la frontera mexicana no enfrentan la condición indocumentada de los inmi- 
grantes en California. Tal diferencia lleva a disentir a los activistas del fiob en Baja California respecto a los activistas del FIOB en California en lo referente a la centralidad de la condición de inmigrantes. Estas diferentes perspectivas sobre la condición de migrante, aun cuando Tijuana está en la frontera y que cerca de 50 por ciento de su población es nacida fuera del estado de Baja California, provienen del peso que tiene la frontera geopolítica en definir a los inmigrantes en Estados Unidos como indocumentados apenas a unos kilómetros de la línea fronteriza.

Si bien, el contexto local impone sus restricciones, la acción colectiva abre la posibilidad de trascenderlo al posicionar a los miembros de la organización en un espacio político común de índole transnacional. Algunos activistas de Baja California participaron en las marchas pro-migrantes en la frontera. Y en los últimos cinco años, después de los talleres es posible registrar una interacción binacional más fuerte entre la coordinación de San Diego y la de Baja California en torno a la recuperación de la memoria indígena y la alianza transfronteriza. Por ejemplo, en las marchas en contra de la construcción del centro de detenciones de inmigrantes para luego deportarlos por parte de la Agencia de Inmigración y Control de Aduanas (ICE, por sus siglas en inglés) en Santa María, en 2014.

En Baja California hay una discusión más nutrida sobre la ausencia de las organizaciones indígenas y de un movimiento indígena en comparación con California. En 2007 fue aprobada la Ley de Derechos y Cultura Indígena de Baja California, donde se reconoce la calidad de pueblos de los inmigrantes temporales o permanentes. Sin embargo, los activistas de este estado tienen un discurso de reafirmación de la condición de residente antes que de migrantes, al parecer como una vía de reafirmación de que no van de paso.

La distinción entre lo urbano y lo rural se expresa en visiones distintas sobre la lucha indígena. Mientras en Tijuana las actividades de la organización se centran en aspectos culturales como las tradiciones o la enseñanza de la lengua, en la zona rural de Ensenada los activistas se centran en los derechos laborales y residenciales. Los líderes en Tijuana son empleados de gobierno y varios de ellos profesores, en tanto en Ensenada los líderes y activistas son trabajadores o extrabajadores agrícolas. En el seno de la 
organización regional la principal diferencia y alianza étnica se da entre purépechas y mixtecos.

Estos encuentros y alianzas producen procesos de reetnización o etnización (Martínez-Casas, 2001) que sólo se pueden entender por la migración y la transferencia de experiencias de liderazgos que pueden crear inclusión, pero a la vez exclusión interétnica. En los años 2005-2006 la Coordinación Estatal en Baja California estaba en manos de una persona de origen purépecha, lo cual creó tensión en un espacio organizativo dominado por activistas mixtecos durante varios años. Después de dos coordinadores de origen purépecha, en 2012 la coordinación regresó a cargo de un dirigente de origen mixteco y los activistas purépechas prácticamente se retiraron.

\section{Juxtlahuaca, Oaxaca: proyecto politico vs.proyecto de desarrollo}

Continuando el trayecto hacia el sur, en Oaxaca la discusión acerca del movimiento migrante es más limitada, aunque emerge durante los encuentros o talleres binacionales. Por ejemplo en los talleres organizados por el FIOB en 2006 no se reflexionó sobre las movilizaciones que se hicieron en Oaxaca durante la discusión de la Ley Sensenbrenner antes mencionada; en cambio hubo una preocupación por el retorno de los jóvenes migrantes procedentes de Estados Unidos y la percepción compartida sobre el cambio de valores en las comunidades de origen. La reivindicación del derecho a no migrar, enarbolado por el Fіов desde 2011, parece encontrar sus raíces en las comunidades oaxaqueñas y en las voces de los activistas de retorno en sus pueblos de origen, después de décadas de trabajo como migrantes, sin documentos y en pobreza continua.

El movimiento indígena en Oaxaca está cruzado por el fuerte activismo popular y magisterial. Si bien el FIOB ha participado en el Congreso Nacional Indígena, ${ }^{13}$ su área de acción más importante en materia indígena es el estado de Oaxaca en cruce con el movimiento magisterial y popular de la APPO. El movimiento indígena oaxaqueño tiene una tradición riquísima en

${ }^{13}$ El Congreso Nacional Indígena (CNI) se fundó entre el 9 y 12 de octubre de 1996, a raíz del Foro Nacional Indígena convocado por el Ejército Zapatista de Liberación Nacional (EzLN) (González, 2014).

$112 \frac{\text { SEGUNDO SEMESTRE } 2014}{\text { MIGRACIÓN Y DESARROLLO NÚM. } 23}$ 
la lucha por los derechos indígenas, sin embargo, ha sido un tanto oscurecida por el movimiento zapatista, que logró una trascendencia mediática a nivel internacional.

A diferencia de las otras regiones, las discusiones en el taller de Oaxaca de 2006 se alejaron del tema indígena y migrante, y se concentraron en dos visiones del proyecto y liderazgo organizativo. Aunque no siempre se expresó en forma explícita, fue posible seguir en las discusiones plenarias del taller la tensión entre lo que se podría llamar la línea política y la línea desarrollista. En la primera está la corriente de opinión que considera que el FIOB debe ser una organización eminentemente política que contribuya al cambio social y político a nivel del estado y el país, por lo que se debe priorizar un tipo de política y ciertos espacios de representación: los partidos políticos. En la segunda línea está la corriente de opinión que considera que el FIOB debe ser una organización que responda a las necesidades de desarrollo de las comunidades y de las personas, por lo que debe priorizar los proyectos productivos y de inversión en infraestructura y servicios y velar por mejorar las condiciones de vida de las comunidades a nivel local.

En un primer acercamiento, esta polémica parece asociar la línea política con una visión masculina y la línea desarrollista con una visión femenina, donde están más involucradas las mujeres. Sin embargo, en las entrevistas en profundidad realizadas en 2006 y 2007se pudo constatar que aunque en esta segunda línea están involucradas un número mayor de mujeres, también hay hombres, dirigentes medios, quienes están muy interesados en promover esta línea de trabajo al interior de la comunidad. Así como también hay mujeres que están muy involucradas en la visión política-partidista y que consideran que esa vía es estratégica para la organización. A la vez, hay dirigentes que consideran que estas dos perspectivas organizativas son viables de convivir al interior de la organización, porque son necesarias. En 2006, la coordinación regional en Juxtlahuaca estaba en manos de una mujer con una nutrida experiencia en proyectos comunitarios y una visión del desarrollo regional. Esta tensión hizo crisis con la expulsión de la dirigente regional y concluyó con el giro a dirigencias masculinas de corte políticopartidista. 
Las asambleas binacionales donde participan delegados de los diferentes estados desde 1994 a la fecha muestran la constante tensión entre lo local y lo transnacional. Actualmente, cuatro ejes de lucha caracterizan el campo transnacional: a) políticas migratorias; b) políticas de desarrollo regional; c) políticas étnicas, con el tema de la autonomía y gobiernos locales indígenas; y d) la formación y reemplazo generacional de liderazgos.

\section{Un acercamiento al liderazgo y su reemplazo en la organización}

Hace ya más de dos décadas que Tijuana fue el escenario de la fundación del FIOB. Era una mañana luminosa y el auditorio del Instituto de Cultura de Tijuana estaba muy concurrido. Ya entonces había activistas de distintas organizaciones que llegaban a constituir el frente, procedentes de lugares distantes y allende la frontera. Todos eran oaxaqueños y la mayoría de esos activistas eran hombres maduros, es decir, en sus cuarentas (Velasco, 2005). ¿Qué ha cambiado desde entonces? La siguiente descripción se basa principalmente en los tres talleres focales realizados por el FIOB en los tres estados durante los años de 2005 y 2006, en los que asistieron un total 64 activistas y miembros, con casi el mismo número de hombres que mujeres, una tercera parte bilingüe español y lengua indígena, otra tercera parte hablan inglés ya sea con lengua indígena o español, y el resto hablantes sólo de español. Tal diversidad lingüística está presente en las asambleas y reuniones de la organización.

Antes de hablar de los nuevos liderazgos asociados a los cambios generacionales, es conveniente conocer el significado de «ser líder» indígena en el seno de la organización en torno a la naturaleza, las características, la ética y las funciones.

\section{La visión emic de los liderazgos}

Los propios activistas de la organización tienen su visión sobre la naturaleza de los liderazgos. Esta visión $\mathrm{emic}^{14}$ se mueve entre dos extremos: uno esen-

${ }^{14}$ Según Geertz (1992: 29), la visión emic se refiere a la interpretación de primer orden que realizan los sujetos sobre su propia vida y sus acciones, a diferencia de la visión etic, que es

$114 \frac{\text { SEGUNDO SEMESTRE } 2014}{\text { MIGRACIÓN Y DESARROLLO NÚM. } 23}$ 
cialista y otro constructivista. Así, hay una corriente de activistas y miembros de la organización que consideran el liderazgo como algo innato; en tanto, otra corriente que asegura que es una cualidad que se adquiere a lo largo de la vida. En esta adquisición de la capacidad de liderazgo la experiencia de dirigir y tener responsabilidades es muy importante; la escolarización puede ayudar, pero hay un elemento simbólico fundamental que es el sufrimiento como una vía sacrificial. Este último elemento es reivindicado por los más viejos y no tanto por los jóvenes.

El papel de los liderazgos para los seguidores combina la visión del «nosotros» $y$ «los otros»: ser voz o ser escucha. Mientras uno enfatiza la capacidad de guiar del líder, el segundo enfatiza la intermediación. La importancia de «escuchar a los demás» fue un rasgo que no sólo alude a los propios, sino a los otros, con quien se tiene que negociar. En Los Ángeles, a diferencia de Oaxaca y Tijuana, se considera una cualidad importante que el líder sea positivo y moderado: «discutir para llegar a acuerdos, no para pelear». En tanto, en Tijuana se le dio particular importancia a la capacidad del líder para negociar entre las diferencias o posiciones distintas, como mediador. Estas perspectivas distintas están alimentadas por el contexto político local, que implica un estilo de hacer política en contextos institucionales distintos, y particularmente un estilo de mediación. Aquí es donde podemos observar la imbricación del contexto con el agente colectivo. En varias ocasiones hubo comentarios, sobre todo de los jóvenes, de que en Oaxaca la política es muy agresiva con «discusiones que llegan a levantarse la voz o con insultos».

La función del líder como "guía» es un punto de coincidencia en las tres regiones. En Oaxaca y en Los Ángeles se subraya la importancia de que el líder esté en contacto y atienda a las comunidades. A la vez, en Tijuana y Oaxaca se menciona la importancia de la función gestora de los líderes ante el Estado. En Oaxaca se enfatiza la necesidad de que el líder propicie el desarrollo, y en Los Ángeles se subraya la importancia de que el líder forme a otros. La función de los liderazgos se asocia también a su visión de la relación con las bases o seguidores.

la interpretación de segundo orden, y que responde a la interpretación del investigador bajo un marco teórico específico. 
La capacidad de los líderes de no imponer decisiones y considerar a los miembros de la organización, especialmente a las bases, fue un rasgo importante. El concepto de base y comunidad parece muy cercano pero tiene ligeros matices. Por ejemplo, cuando se habla de «la base» se refiere a la organización en conjunto, mientras que cuando se habla de "comunidades» parece hacerse alusión al vínculo de la organización con la comunidad local, dispersa territorialmente. A la vez, también refleja dos formas distintas de hablar de liderazgos entre los miembros. Los que hablan de bases tienen un discurso político cercano a los partidos políticos o a las organizaciones políticas de oposición, mientras que los que hablan de comunidades se refieren a procesos organizativos más locales y concretos, cercanos a proyectos organizativos y productivos de pequeña escala (más cercano al grassroots), que no necesariamente son políticamente opositoras al gobierno.

En las tres regiones coincidieron en que el líder indígena era distinto en su ética respecto de otro tipo de líderes, aunque no siempre es claro a quién tienen de referencia. Entre los rasgos más importantes del liderazgo indígena está la honestidad y la disposición para servir a la comunidad. Este rasgo se acompaña con la percepción de que es más difícil que el líder indígena traicione a la comunidad por su sentido de servicio; en Los Ángeles se enfatizó, además de esta disposición, la importancia de la práctica de rendición de cuentas. Un rasgo polémico entre los asistentes a los talleres es la necesidad de que el líder indígena hable lengua indígena. Este rasgo se puso en cuestión particular y paradójicamente en el estado de Oaxaca, donde se enfatizó más el rasgo político a diferencia de California y Baja California donde adquirió mayor importancia lo cultural; es decir, una persona puede ser líder indígena aunque no sea hablante de lengua indígena, pero que se asuma como indígena o esté identificado con los indígenas; en suma, puede ser un outsider, étnicamente hablando, como lo encuentra Edelman (1999: 195) para el caso del movimiento campesino en Costa Rica.

En el taller de 2006, el origen de la condición indígena del líder se explicó en forma diferenciada en cada región. En Oaxaca se menciona que nace de la situación de marginalidad de los indígenas respecto de los mestizos; en 
Los Ángeles se enfatiza más la importancia de la tradición comunitaria y la espiritualidad, y en Tijuana se enfatiza la lengua indígena por su importancia como medio de comunicación y de representación.

Como se observa en la descripción anterior, el significado de ser líder navega entre una visión esencialista y una visión constructivista: se nace o se hace un líder. Al mismo tiempo, la relación con la «base» o "comunidad» mezcla prácticas de relación líder-seguidores de dos visiones políticas distintas: la de las organizaciones de izquierda y de los partidos políticos, y la de la vida comunitaria local indígena. La combinación de elementos como ser guía o gestor, también concentra dos visiones: la comunitaria y la política, por llamarle de algún modo a esta última visión que se enmarca en el sistema político del Estado moderno.

Finalmente, el significado de ser líder indígena se alimenta tanto de la ética de la autoridad tradicional, básicamente por su orientación colectiva y su sentido de servicio, como de la figura de autoridad en un sistema político institucionalizado y más amplio, donde existe una forma clara de rendición de cuentas. La realidad nos presenta un rostro más complejo de la autoridad y los liderazgos indígenas que las dualidades que sirven de guía analítica.

Jóvenes del FIOB y los posibles nuevos liderazgos

El tema de la generación nos plantea la cuestión de los jóvenes, ${ }^{15}$ y por lo tanto del reemplazo de liderazgos al interior de la organización y la renovación del proyecto colectivo. A continuación sólo se habla de los jóvenes en Los Ángeles y en Oaxaca, debido a que en Tijuana han estado ausentes de los encuentros y talleres. ${ }^{16}$

${ }^{15}$ Se toma la definición de jóvenes por el rango de edad que establece el Instituto Mexicano de la Juventud: de 12 a 29 años de edad. Disponible en: http://www.imjuventud.gob.mx/ (consultado el 10 de marzo de 2014).

${ }^{16}$ Hay un registro de jóvenes mujeres activas en el Valle de San Quintín, alrededor de la radio indígena La Voz del Valle y de la Casa de la Mujer Indígena, pero que no están integradas al FIOB. 
Según el registro de los talleres 2005-2006, dos terceras partes de los activistas se incorporaron después de 2000; lo cual nos dice que existe un grupo importante de miembros con dos décadas de participación en la organización, y a su vez un grupo significativo de líderes, activistas y miembros que se incorporaron en la última década. Dado que esta organización surge con la migración, es importante subrayar esta continuidad en las dos últimas décadas, lo que habla de cierta estabilidad en el tiempo, pero a la vez de una renovación constante. ${ }^{17}$

En términos de la participación de jóvenes, los dos contextos fueron muy diferentes. En los talleres de Los Ángeles, California, asistieron varios jóvenes, quienes mostraron una participación muy activa en las discusiones. En su condición de integrantes de la organización, los jóvenes hombres y mujeres anidan su experiencia en los eventos culturales del fiов. Muchos de ellos son estudiantes universitarios con liderazgo en sus comunidades escolares en torno a temas culturales (asociados con sus lugares de origen) y como inmigrantes. Y en los últimos años, con las deportaciones del interior después de una larga residencia en Estados Unidos, se han incorporado a las filas de los Dreamers o bien en pro de la reforma migratoria aparentemente en puerta. Algunos de estos jóvenes, sobre todo los de los valles centrales de California, Fresno y Madera, forman parte del Equipo de Cronistas Oaxacalifornianos (ECO, 2013).

Algunos de ellos son los hijos o sobrinos de miembros de la organización. La participación en el FIOB se asocia con su condición de inmigrantes e indígenas en California y su proceso de incorporación a la sociedad local y nacional estadounidense. Una joven se enteró de la organización por sus profesores universitarios, quienes los alentaron a buscar a la organización; lo cual puede ser un indicio de las políticas de identidad en las universidades asociado al modelo multicultural estadounidense. Algunos testimonios vertidos en los talleres nos dan indicio de este proceso y el papel de la organización.

${ }^{17}$ En el seguimiento de las organizaciones oaxaqueñas en Baja California y California he detectado la salida constante de miembros. Sin embargo, mientras algunos salen por diferencias con las organizaciones, otros se alejan y ante una coyuntura determinada vuelven a incorporarse a la misma organización u otra.

$118 \frac{\text { SEGUNDO SEMESTRE } 2014}{\text { MIGRACIÓN Y DESARROLLO NÚM. } 23}$ 
[...] Yo llegué a Estados Unidos cuando estaba tratando de encontrar mi propia identidad. Los estudiantes que viven en Oaxaca no entienden su cultura; [sólo] entienden su cultura cuando salen [...] mi abuelito me regañaba pero yo pensaba que él era abuelo, y pensaba "i̇qué sabe él de la vida?» [...] Cuando yo llegué en el 2000 a Fresno vi el anuncio de la Guelaguetza, ${ }^{18}$ la cual yo conocía sólo por discos de mi abuelo [...] y entonces conocí a Leoncio [...] él me motivó y me ayudó $[\ldots]$ y me interesó incorporarme al ғIов por su trabajo con la cultura» (Jorge). ${ }^{19}$

[...] yo viví 13 años en el Distrito Federal, pero siempre obtenía rechazo de parte de mi familia [en el pueblo], y tenía resentimiento. La familia en el pueblo me rechazaba, porque decían que yo no era oaxaqueña sino chilanga ${ }^{20}[\ldots]$ y cuando llegué a Estados Unidos yo no sabía nada de Oaxaca [...] Entonces me enteré de un evento de Guelaguetza [...] y fue cuando conocimos el frente [FIOB] $[\ldots]$ conocí sus bailables folklóricos. Lo tuve que dejar porque tenía que prepararme más [ir a la escuela], tenía que competir con los nacidos en Estados Unidos... por ahora ya estoy en la universidad [...] y ahora ya regresé al ғіов (joven mujer). ${ }^{21}$

Los pasajes orales de estos dos jóvenes nacidos en México y ahora residentes en Estados Unidos son una pequeña muestra de las preocupaciones que atraen a los jóvenes a la organización. A diferencia de Oaxaca, la sobrevivencia económica y el empleo, las fuentes de ingreso, no son el centro de sus reflexiones, sino la identidad y la cultura, y la necesidad de estudiar en un contexto de diversidad migratoria, incluso para los procedentes de México.

Por otra parte, en Oaxaca participaron varios jóvenes en el taller, particularmente mujeres jóvenes y adolescentes; lo cual puede estar asociado a la

${ }^{18}$ Guelaguetza es una tradición prehispánica de intercambio entre los pueblos oaxaqueños, principalmente en los valles centrales de Oaxaca y con más arraigo en los pueblos zapotecos. Sin embargo, en los lugares de migración como el Distrito Federal y California ha sido apropiada y reapropiada por otros pueblos oaxaqueños, como los mixtecos.

${ }^{19}$ Participante en el taller de Los Ángeles el 20 y 21 de enero de 2007.

${ }^{20} \mathrm{La} w$ «Chilango» refiere a una persona nacida y crecida en el Distrito Federal, la capital de México. Fuera del Distrito Federal, generalmente es un término despectivo y se utiliza con connotación negativa.

${ }^{21}$ Participante en el taller de Los Ángeles el 20 y 21 de enero de 2007. 
migración de los hombres. Estas jóvenes están participando en proyectos productivos a través de sus madres, hermanas, tías o como jefas de hogar. $\mathrm{O}$ sea que los proyectos productivos son una vía para incorporar a los jóvenes a la organización. En ellos, los jóvenes están encontrando (sobre todo las mujeres) una ocupación que complementa sus estudios de secundaria y les abre una vía de capacitación informal a través de los talleres que ofrece el ғіов. Según las entrevistas, las actividades que promueve la organización se insertan en la vida comunitaria con mucha naturalidad, por lo que los miembros de las familias participan con fluidez. Los proyectos productivos y las cajas de ahorro están dirigidas y constituidas principalmente por mujeres cónyuges o jefas de familia que generalmente se auxilian de sus hijas adolescentes para llevar la administración de los proyectos o a quienes piden apoyo para asistir a los talleres de capacitación.

Algunas jóvenes que asistieron al taller en Oaxaca estaban representando a sus madres como miembros de la organización. Notamos que la presencia de las jóvenes incomodó a algunos hombres líderes de la dirigencia estatal. Ellos se refirieron abiertamente a estas «jóvenes que sólo venían por los proyectos y que no tenían conciencia política». Sin embargo, en las entrevistas pudimos observar que, en efecto, estas jóvenes participan en los proyectos productivos como una actividad familiar, pero que viven con entusiasmo las actividades de la organización, particularmente la realización de talleres. En sus cédulas de registro ante la pregunta «żqué esperas de la organización?» se encontraron respuestas como: «apoyar a la comunidad» de una joven de 14 años; «que se tome en cuenta a la comunidad y seguir participando en el FIOB» en una joven de 16 años; «ser una persona independiente» de una joven de 19 años. La distancia entre los discursos políticos de la dirigencia estatal del FIOB (con excepción de la coordinadora regional) y estas jóvenes es amplia.

Estas jóvenes pertenecen a familias con varios de sus integrantes en Estados Unidos, generalmente padre y hermanos mayores. Según relataron, sus hermanas, al casarse, se habían ido hacia el norte con sus esposos, o bien se habían casado y estaban en una larga espera de reunirse con sus esposos. Estos contextos familiares nos permiten valorar la importancia de estos proyectos productivos y de las actividades que se realizan en la comunidad

$120 \frac{\text { SEGUNDO SEMESTRE } 2014}{\text { MIGRACIÓN Y DESARROLLO NÚM. } 23}$ 
para estas jóvenes, que muy pronto terminarán la secundaria y no tendrán más opción, "que tal vez casarse y migrar, como lo han hecho sus hermanas». En la perspectiva de algunas líderes regionales de Juxtlahuaca, estas jóvenes se están formando como una generación nueva de mujeres líderes que saben leer y escribir, que crecieron en familias divididas por la migración en pueblos con pocos hombres y sin opciones de empleo. Son las hijas más pequeñas de la familia, por lo que hay una especie de vacío generacional entre su madre y ellas. Algunas entrevistas transcurrieron con una madre de más de cincuenta años con una hija de catorce años, ambas participando en los comités de proyectos productivos de las comunidades.

En cada lugar el reto de incorporar a jóvenes y formarlos como líderes es distinto, porque las formas de ser jóvenes en cada lugar son distintas y sus intereses dependen de sus contextos regionales, aunque comparten el horizonte de discriminación étnica transnacional. Sin embargo, es posible registrar el papel de soporte social y cultural que encuentra en la organización en una etapa estratégica de su ciclo de vida.

\section{Conclusiones}

Estudiar los liderazgos indígenas surgidos en la experiencia migratoria a Estados Unidos lleva a replantear las visiones dicotómicas que usamos para analizar, pero que olvidamos cuestionar a partir de los propios datos generados en forma empírica. Bonfil (1995) lo señaló acertadamente a principios de los años noventa con el surgimiento de nuevos liderazgos en el contexto de las migraciones indígenas urbanas. ว̇Pero realmente son nuevos liderazgos? ¿̇A qué se refería Bonfil cuando decía esto? En forma sucinta, podemos decir que aludía a la relación básica entre líder y comunidades indígenas. Lo que observamos en el cuerpo de este artículo es que en la medida en que la comunidad indígena cambia durante la migración con nuevas territorialidades, prácticas culturales y nuevos intereses como colectividad, también se transforma la autoridad indígena y los liderazgos como formas de representación política y cultural. 
En el recuento de los distintos contextos locales que dan base social a una organización como el FIOB es claro que los intereses locales y las luchas particulares siguen siendo vitales en la política étnica como indígenas migrantes. Sin embargo, el horizonte en que estas luchas particulares toman sentido delinea ejes de lucha política y cultural que difícilmente se agotan en el nivel de la localidad o la región, sino que lo trascienden hacia un campo político transnacional: más allá de México, más allá de Estados Unidos.

¿Se puede caracterizar a los liderazgos por su orientación local o transnacional? En un primer momento esa distinción puede ser útil, pero a la vez dificulta entender que un mismo activista pueda ejercer una u otra orientación según sea necesario y según el contexto de actuación. Un liderazgo en California puede ser sumamente exitoso por responder a la visión de «formación de otros» que esperan sus seguidores, mientras que puede no serlo en Oaxaca, donde se espera más el papel de guía o gestor. Estas funciones parecen obedecer más a los contextos locales de hacer política corporativa en Oaxaca o en Baja California, a diferencia de California, donde hay una relación de ciudadanía más directa e individualizada. Sin embargo, el liderazgo cultural o la representación cultural en California es sumamente importante, porque el contexto altamente etnizado y de discriminación como indígenas y migrantes coloca a los liderazgos como referentes identitarios fundamentales. Por ello, las áreas de reproducción cultural generan una gran actividad entre los jóvenes activistas y líderes en ciernes en California, con un énfasis muy marcado en la identidad, la educación, el idioma y los documentos como elementos de integración estratégicos. Todos los anteriores son temas de interés para los nuevos liderazgos de indígenas hispanoamericanos, como lo confirman los talleres de descolonización y rescate de la memoria de 2013 (véase ECO, 2013).

Los distintos liderazgos se alimentan de sendas de experiencia común que los distingue generacionalmente: el sistema de cargos, las luchas obreropopulares en las ciudades, las luchas de jornaleros agrícolas, las étnicas en el contexto mexicano y las de inmigrantes y ciudadanía en Estados Unidos. Pero esas sendas de experiencia común se matizan en los espacios de discusión y movilización donde los activistas, líderes, autoridades de distintos contextos regionales se encuentran, así como de diferentes generaciones no

$122 \frac{\text { SEGUNDO SEMESTRE } 2014}{\text { MIGRACIÓN Y DESARROLLO NÚM. } 23}$ 
sólo por la edad, sino de migrantes. El polo entre tradición y modernidad es cuestionado en los procesos de liderazgos multiterritoriales, donde los jóvenes activistas de Estados Unidos se adscriben a los usos y costumbres, aunque también los critican en términos de las relaciones de género por ejemplo. Su contexto étnico está definido por la diferencia nacional de los migrantes, pero también por su origen indígena en México. O bien, los activistas y autoridades de Oaxaca se adscriben a la importancia de una reforma migratoria que permite una ciudadanía equitativa de sus familiares y paisanos y como líneas de lucha. Así, parece que los procesos de liderazgos no están alejados de las comunidades locales y regionales que los producen, pero a la vez de los horizontes amplios de la política transnacional con la que definen su horizonte de contienda.

\section{Bibliografía}

Bartolomé, Miguel Alberto (1997), Gente de costumbre y gente de razón: las identidades étnicas en México, México, Siglo XXI, INI.

BonfIL, Guillermo (1995), «El pensamiento político indio: proyecto de civilización y demandas inmediatas", en Obras escogidas de Guillermo Bonfil, vol. 3, INI, INAH, Conaculta, Fideicomiso Fondo Nacional de Fomento Ejidal-Sra, CIESAS.

Bourdieu, Pierre (1982), Ce que parlerveutdire, París, Libraire Artheme Fayard.

Edelman, Marc (1999), Peasants Against Globalization. Rural Social Movements in Costa Rica, Stanford, California, Stanford University Press.

(2003), «Movimientos sociales y campesinos. Algunas reflexiones», conferencia en el Instituto de Investigaciones Sociales, Universidad de Costa Rica, San José, Costa Rica, $1^{\circ}$. de julio.

Equipo de Cronistas Oaxacalifornianos (eCo) (2013), Voces de jóvenes indígenas oaxaqueños en el Valle Central: Forjando nuestro sentido de pertenencia en California, UC, Centre for Collaborative Research for an Equitable California, Informe de Investigación, núm. 1, julio, Universidad de California.

Hernández, Jorge y Andrew Selee (2013), «Introducción», en Jorge Hérnandez-Díaz y Andrew Selee (coords.), Organización política y gobernabilidad en territorios indígenas de América Latina, México, Miguel Ángel Porrúa, pp. 7-15. 
Hernández Morales, María Eugenia (2012), «ßOaxAmericans»: La construcción de la identidad étnica en las y los jóvenes de origen indígena de Oaxaca en Madera y Fresno, California, Estados Unidos», tesis de maestría en Estudios Culturales, Tijuana, Colegio de la Frontera Norte.

GeERTz, Clifford (1992), La interpretación de las culturas, Barcelona, Gedisa.

González García, Carlos, Congreso Nacional Indígena (2014), "Diez años en la brecha», La Jornada, en http://www.jornada.unam.mx/2006/09/18/oja113-cni. html (consultado el 24 de noviembre de 2014).

Gramsci, Antonio (1998), "The intellectuals», en Antonio Gramsci, Selections from the Prison Notebooks 3-14, Londres, Lawrence and Wishart.

Martínez-CASAS, Regina(2001), "Una cara indígena: La resignificación de la cultura otomí en la ciudad», tesis de Doctorado en Ciencias Antropológicas, México, Universidad Autónoma Metropolitana-Iztapalapa.

Melucci, Alberto(1999), Acción colectiva, vida cotidiana y democracia, México, Colegio de México.

Rivera-Salgado, Gaspar y Luis Escala (2005), "Identidad colectiva y estrategias organizativas entre migrantes mexicanos indígenas y mestizos», en Jonathan Fox y Gaspar Rivera-Salgado (coords.), Indígenas mexicanos migrantes en los Estados Unidos, México, Universidad Autónoma de Zacatecas, Miguel Ángel Porrúa. Romero-Hernández, Odilia, Centolia Maldonado Vásquez, Rufino DomínguezSantos, Maylei Blackwell y Laura Velasco (2013), "Género, generación y equidad: los retos del liderazgo indígena binacional entre México y Estados Unidos en la experiencia del Frente Indígena de Organizaciones Binacionales (FIOB)», en Charles R. Hale y Lynn Stephen (eds.), Otros saberes. Collaborative Research on Indigenous and Afro-Descendant Cultural Politics, Santa Fe, Nuevo Mexico, School for Advanced Research.

SMELSER, Neil (2003), «On Comparative Analysis, Interdisciplinarity and Internationalization in Sociology", International Sociology, Londres, vol. 18, núm. 4, pp. 643-657.

Stephen, Lynn (2007), «We are Brown, We are Short, We are Fat... We are the Face of Oaxaca»: Women Leaders in the Oaxaca Rebellion», Socialism and Democracy, Somerville, Massachusetts, vol. 21, núm. 1, pp. 97-112.

Touraine, Alain (1981), The Voice and the Eye: An Analysis of Social Movements, Cambridge, Cambridge University Press.

$124 \frac{\text { SEGUNDO SEMESTRE } 2014}{\text { MIGRACIÓN Y DESARROLLO NÚM. } 23}$ 
Velasco, Laura (2005), Mixtec Transnational Identity, Tucson, Arizona, University of Arizona Press.

VeLASCO, Laura y Marie Laure Coubès en colaboración con Tito Alegría, Ietza Bojórquez, Óscar Contreras, Alberto Hernández y Silva Mejía (2013), Reporte sobre dimensión, caracterización y áreas de atención a mexicanos deportados desde Estados Unidos, Tijuana, Colegio de la Frontera Norte, en http://www. colef.mx/estudiosdeelcolef/reporte-sobre-dimension-caracterizacion-y-areasde-atencion-mexicanos-deportados-desde-estados-unidos (consultado el 18 de julio de 2014). 
